comparison with a statistical model based on baseline variables. I would like to express three concerns about the technical details of this article.

First, the kappas they report are Cohen's kappas whereby the disagreement between "full recovery within 6 months" and "partial recovery" is penalised equally to disagreement between "full recovery within 6 months" and "no recovery". Clinically, however, the former is apparently less grave than the latter. More appropriate statistics would be weighted kappas, which are 0.31 (95\% CI 0.15-0.46) for GP prognosis for depression, 0.35 (95\% CI 0.16 $0.54)$ for GP prognosis for anxiety, 0.56 (95\% CI 0.43-0.70) for model prognosis for depression and 0.51 (95\% CI 0.33-0.69) for model prognosis for anxiety. These figures are appreciably larger than those originally reported.

Moreover, regardless of whether we use Cohen's kappas or weighted kappas, the authors did not examine whether the GP prediction is indeed statistically significantly worse than the model's. The reported $95 \%$ confidence intervals overlap, and we do not know whether the clinicians are actually performing worse than the maximally attainable model.

Third, as the authors rightly note in the Discussion, their way of using the total sample to construct a predictive model may have 'overfitted' the model to the data and produced artificially inflated agreement. A more ideal way may have been the 'leavingone-out method' (Lachenbruch, 1975), in which analysts would repeatedly build a model based on a sample minus one observation and examine whether each model could predict the one excluded observation.

In this connection it may be worthwhile to point out that the comparison between human performance and that of a statistical model is a theme repeatedly found in clinical psychology (Meehl, 1954; Goldberg, 1970). These studies conclude that, because of the inevitable random error in human judgement, the latter almost always outperforms the former. It will, therefore, be most interesting to see how, in the authors' next round of proposed investigation, clinicians can improve their performance if they are given feedback on prognostic factors.

Goldberg, L. R. (1970) Man versus model of man: a rationale plus evidence for a method of improving on clinical inferences. Psychological Bulletin, 73, 422-432.

Lachenbruch, P. A. (1975) Discriminant Analysis. New York: Hafner.
Meehl, P. E. (1954) Clinical Versus Statistical Prediction A Theoretical Analysis and a Review of the Evidence. Minneapolis, MN: University of Minnesota Press.

van den Brink, R. H. S., Ormel, J., van der Meer, K., et al (200I) Accuracy of general practitioner's prognosis of the I-year course of depression and generalised anxiety. British Journal of Psychiatry, 178, 18-22.

T. A. Furukawa Department of Psychiatry, Nagoya City University Medical School, Mizuho-cho, Mizuho-ku, Nagoya 467-860I, Japan

\section{The stigma of suicide}

The Royal College of Psychiatrists is leading a campaign to reduce the stigma attached to mental illness. Stigmatisation of suicide has very deep roots in our collective thinking and judgement. Suicide was tolerated by the Greeks and Romans (Alvarez, 1990), but Aristotle argued that suicide weakens the economy and upsets the gods, and in so-doing he initiated stigmatisation of the act. Hinduism and Buddhism, among other Eastern religions, have not had a traditionally negative view of suicide. In the JudaeoChristian tradition, stigma against suicide is not evident until the fourth century; the Bible does not condemn suicide (Barraclough, 1992), but St Augustine considered suicide as unacceptable within Christian values (Pritchard, 1996). Gradually, the stigma against suicide intensified in Europe and became a great sin, shame and eventually a crime. A number of philosophers and writers including William Shakespeare sought to encourage a more understanding and compassionate view but this movement had little impact before Durkheim's studies made clear the social rather than moral origins of suicide (Retterstol, 1993). Although suicide and attempted suicide were decriminalised in 1961 (Levine \& Pyke, 1999), we have practised since within a culture of ambivalence wherein stigma is neither high nor totally eliminated. Indeed, the multicultural/multifaith dimension within society and its thinking has complicated matters considerably.

The stigma surrounding suicide remains just high enough to discourage people especially the elderly - from talking about their suicidal thoughts. Some people feel that they might be labelled as weak, lacking faith, coming from bad families or indeed 'mad' if they were to declare their suicidal thoughts. This does not help when we are trying to detect early signs of suicide or reaching out to help victims of despair.
Any approach to prevent suicide should include the removal of blame and stigmatisation of that individual and his or her family. One would hope that all teachers and professionals from the different faiths will take into account this insight into the condition. Scientific approaches and spiritual approaches can work together in order to eliminate this kind of stigma and to make people more comfortable in trying to seek help in their moments of despair.

Alvarez, A. (1990) The Savage God: A Study of Suicide pp. 59-93. New York: W.W. Norton.

Barraclough, B. M. (1992) The Bible suicides. Acta Psychiatria Scandinavica, 86, 64-69.

Levine, M. \& Pyke, J. (1999) Levine on Coroners' Courts. London: Sweet \& Maxwell.

Pritchard, C. (1996) Suicide - The Ultimate Rejection? A Psychological Study, pp. 9-28. Buckingham: Open University Press.

Retterstol, N. (1993) Suicide: A European Perspective, pp. 9-2I. Cambridge: Cambridge University Press.

G. Tadros, D. Jolley Wolverhampton Health Care NHS Trust, Penn Hospital, Penn Road, Wolverhampton WV4 5HA, UK

\section{Who is politicising psychiatry in China?}

Having researched on qigong-related mental health problems in China, I am upset to read the statement of Lyons (2001), based indirectly on estimates from Amnesty International and a letter to the Lancet, that "Soviet-style psychiatry is alive and well in the People's Republic".

In China, resurgence of interest in qigong ('exercise of vital energy') started as early as 1980, when Chinese people were recovering from the social chaos brought about by the Cultural Revolution (1966-1976). It is worth noting that qigong-induced mental disorder was reported by Chinese psychiatrists long before recent accusations that psychiatry in China is used to imprison people who practise a specific kind of qigong known as falungong. There have been a sizeable number of controlled phenomenological, treatment and outcome studies published in the past two decades that testify that qigong-related mental disorders do not fall into a specific disease category recognised in the modern classifications (see Lee, 1996, for a brief review). In my own field studies, I interviewed people who suffered from acute psychosis induced by the inappropriate practice of qigong in several regions of China as well as in Hong Kong. The condition is intriguing but real, and is deserving of 
more research from both medical and social science perspectives (Lee \& Yu, 1995).

It has been estimated that not less than $5 \%$ of people in China practise qigong. The proportion of such people who develop psychiatric complications remains unknown but is likely to be very small. None the less, China has a population of 1.3 billion. The estimate that 600 people received psychiatric treatment for qigong-induced mental disorder cannot automatically be assumed to represent an abuse of psychiatry. China is a huge, heterogeneous and rapidly transforming country in which the standard of psychiatry varies widely from region to region. So the possibility of unethical psychiatric practice certainly exists. Additionally, in the current period of market reforms, the Chinese Government has withdrawn central funding for health care, and hospitals are forced to generate an increasingly large part of their own incomes. As a result, China is in the paradoxical position of having an inadequate number of psychiatric beds, yet at the same time a large number of beds that are unoccupied because families cannot afford to send patients to hospitals on a fee-for-service basis (Lee \& Kleinman, 2000).

As a China researcher who can be critical of recent social and moral changes in the country, I feel obliged to point out that even if unethical psychiatric practice existed in China (as it does in the USA, UK, or elsewhere), it would simply not be on the scale seen in the former Soviet Union. I must conclude that the views of Lyons and others who reach similar conclusions (e.g. "Contortions of Psychiatry in China", New York Times, 25 March 2001) are premature and even dangerous, and beg the question of who really is politicising psychiatry in China. As an international leader in psychiatry, the World Psychiatric Association must undertake its review of the accusations against Chinese psychiatrists prudently.

Lee, S. (1996) Cultures in psychiatric nosology: the CCMD-2-R and international classification of mental disorders. Culture, Medicine, and Psychiatry, 20, 421-472.

_ \& Yu, H. (1995) The evaluation of qigong induced mental disorder as a Chinese culture-bound syndrome (in Chinese). Archives of Psychiatry, 4, 222-225.

—\& Kleinman, A. (2000) Grave new world: is reform disease or cure for China's mentally ill? Harvard China Review, 2, 72-75.

Lyons, D. (200I) Soviet-style psychiatry is alive and well in the People's Republic (letter). British Journal of Psychiatry, 178, 380-381.

S. Lee Department of Psychiatry, II/F, Prince of Wales Hospital, Shatin, Hong Kong

\section{Lest we forget, again}

May I comment upon and add to the recent paper by Jones \& Wessely (2001).

The deployment of psychiatrists in both World Wars was a constant battle waged against ignorance and prejudice (Shephard, 2000), even when as well prepared and aware as the Americans prior to the First World War (Salmon, 1917). It appears that each generation is doomed to relearn the lessons of combat psychiatry.

Although the authors describe its effects, they make no mention of combat psychiatry's touchstone, 'evacuation syndromes'. Described by the Russians in 1904-1905 they revealed what happened when a soldier's social role is replaced by that of a patient, i.e. the 'fixation' of symptoms (Awtokratow, 1907). A similar type of problem may be seen in civil practice (Hadler, 1996).

Combat-related military diagnostic practice has been, and remains, problematic (especially in research) as the aim is to minimise stigma, normalise the experience where possible and positively emphasise recovery (McCarroll et al, 1993). During combat, military medical officers have the moral and ethical dilemma that their 'patient' is the organisation rather than the individual and is affected by whether they relate predominantly to the majority (civilian) or minority (military) culture. While doctors may feel compassion towards those who break down, evacuation may mean the lives of those who remain behind are made more uncomfortable and dangerous - hardly surprising therefore that peers or commanders may not view breakdown sympathetically.

Acute or post-combat psychological reactions are multi-factorial in aetiology. Their genesis is the product of an interaction between the individual, the event, the environment (before, during and after) and the culture from which individuals hail and to which they return. Hence, rates may range from 0 to $100 \%$ in the same theatre of operations (Noy et al, 1987). Although there is a direct relationship between physical and psychological casualty rates, this relationship may be stated more bluntly: winners get fewer psychological casualties.

The word 'fatigue' is used loosely by Jones \& Wessely. During the discussion of the Normandy offensive they state that "high percentages were also a function of widespread battle fatigue in soldiers who had already fought in North Africa ...."; this should read war-weariness. In 1939 , unlike 1914, there was no euphoria about the impending war and throughout the Second World War there was a feeling that "I've done my bit, now it's time for someone else to do their's" - this certainly seemed true in experienced veterans recalled to duty in Normandy and Korea.

Although often forgotten, the lessons of military psychiatry are as true today as in 1904-1905. Military psychiatrists cannot escape the social consequences of their labelling behaviours - perhaps this is the current combat psychiatry lesson to be forgotten!

Awtokratow, P. M. (1907) Die Geisteskranken im russischen Heere während des Japanischen Krieges. Allgemeine Zeitschrift für Psychiatrie, 64, 286-319.

Hadler, N. M. (1996) If you have to prove you are ill, you can't get well: the object lesson of fibromyalgia. Spine, 2I, 2397-2400.

Jones, E. \& Wessely, S. (200I) Psychiatric battle casualties: an intra- and interwar comparison. British Journal of Psychiatry, 178, 242-247.

McCarroll, J. E., Orman, D. T. \& Lundy, A. C. (1993) Differences in self- and supervisor-referrals to a military health clinic. Military Medicine, 158, 705-708.

Noy, S., Belenky, G. \& Solomon, Z. (1987) Battle stress, morale, cohesion, combat effectiveness, heroism and psychiatric casualties: the Israeli experience. In Contemporary Studies in Combat Psychiatry (ed. G. Belenky), pp. II-20. New York: Greenwood Press.

Salmon, T.W. (1917) The care and treatment of mental diseases and war neuroses ("shell shock") in the British Army. Mental Hygiene, I, 509-547.

Shephard, B. (2000) A War of Nerves. Soldiers and Psychiatrists 1914-1994. London: Jonathan Cape.

I. P. Palmer Department of Psychiatry, Royal Defence Medical College, Fort Blockhouse, Gosport, Hampshire POI2 2AB, UK

Authors' reply: Constructive criticism from a collaborator is always welcome. Palmer is right to point out the importance of evacuation syndromes, although sadly no psychiatric casualty statistics are readily available from the Russo-Japanese war. $\mathrm{He}$ also properly points out the broader cultural environment in which psychological casualties are framed. However, the purpose of our paper was to suggest that these factors shape the expression of these disorders rather than their incidence, which is largely determined by battle intensity irrespective of place or period. This explains why rates may vary considerably in the same theatre of operations as we demonstrated (Jones \& Wessely, 2001, Table 4). Although it is generally true that "winners get fewer 